\title{
WIND TURBINE DESIGNS FOR URBAN APPLICATIONS: A CASE STUDY OF SHROUDED DIFFUSER CASING FOR TURBINES
}

\section{Highlights}

1. The paper reviews the current state of urban wind turbines and their challenges

2. The performance of existing urban wind turbines are compared using power coefficient

3. A case study of a shrouded diffuser casing for small roof-mounted turbines is tested using CFD to provide a proof of concept for wind power augmentation

4. Recognizing the challenges, solutions to the efficiency of urban wind turbines are investigated 



\title{
WIND TURBINE DESIGNS FOR URBAN APPLICATIONS: A CASE STUDY OF SHROUDED DIFFUSER CASING FOR TURBINES
}

\author{
Aierken Dilimulati ${ }^{1}$, Ted Stathopoulos ${ }^{2}$, Marius Paraschivoiu ${ }^{3}$ \\ ${ }^{1,3}$ Department of Mechanical, Industrial \& Aerospace Engineering, Concordia University, \\ Montreal, Quebec, Canada \\ ${ }^{2}$ Department of Building, Civil and Environmental Engineering, Concordia University, \\ Montreal, Quebec, Canada
}

\begin{abstract}
:
The increased demand for renewable energy and the energy efficient building designs have motivated significant research into the improvement of urban wind power technologies. There have been studies examining the performance of both existing and new turbine technologies. This paper reviews the state-of-the-art of urban wind energy by examining the various types of urban wind turbine designs, with a view to understand their performance and the synergy between the turbines and the urban environments. It also considers a flanged diffuser shroud mechanism - a fluid machine, mounted on rooftop of buildings used as casing for small wind turbines to improve turbine performance by using mainly CFD. The diffuser shroud mechanism can draw the airflow over buildings utilizing its special features such as, cycloidal curve geometry at the inlet and a vortex generating flange at the outlet, to guide and accelerate the airflow inside. The performance of the fluid machine is optimized parametrically. The mechanism is modeled on a building rooftop in a real test site in Montreal, Canada with real statistical wind data. The CFD result confirms the functionality of the fluid machine to take advantage of the airflow over buildings in complex built-environments for wind power generation.
\end{abstract}

Keywords: Urban Energy, Wind Turbines, Diffuser Shroud casing 


\section{Nomenclature}
A $\quad=$ Rotor blade swept area $\left(\mathrm{m}^{2}\right)$
$\mathrm{A}^{*} \quad=$ Diffuser exit area $\left(\mathrm{m}^{2}\right)$
$\mathrm{C}_{\text {power }} \quad=$ Power coefficient
$\mathrm{Cp} \quad=$ Pressure Coefficient
$\mathrm{C}_{\mathrm{s}} \quad=$ Roughness constant
$\mathrm{C}_{\mathrm{u}} \quad=k \varepsilon$ turbulence model constant
HAWT $=$ Horizontal axis wind turbine
$\mathrm{K}=$ Von Karman constant
$\mathrm{K}_{\mathrm{S}, \mathrm{ABL}}=$ Equivalent sand-grain roughness height for $\mathrm{ABL}$
Lt $\quad=$ Diffuser axial length
$\mathrm{L}=\operatorname{Re}$ Characteristic length $(\mathrm{m})$
$\mathrm{P}_{\text {wind }} \quad=$ Wind power $(\mathrm{W})$
$\mathrm{R}=$ Radius of rotor blades $(\mathrm{m})$
$\operatorname{Re} \quad=$ Reynolds number
$\operatorname{TSR}($ or $\lambda)=$ Tip speed ratio
$\mathrm{U} \quad=$ Wind speed $(\mathrm{m} / \mathrm{s})$
$\mathrm{U}^{*}{ }_{\mathrm{ABL}} \quad=\mathrm{ABL}$ friction velocity
VAWT $=$ Vertical axis wind turbine
$\mathrm{Z}_{0} \quad=$ Aerodynamic roughness
$\rho \quad=$ Air density $\left(\mathrm{kg} / \mathrm{m}^{3}\right)$
$\omega \quad=$ Specific dissipation rate $\left(\mathrm{s}^{-1}\right)$
$\mathrm{v} \quad=$ Kinematic Viscosity $\left(\mathrm{m}^{2} / \mathrm{s}\right)$
$\mathrm{k}=$ Turbulent kinetic energy $\left(\mathrm{m}^{2} / \mathrm{s}^{2}\right)$
$\varepsilon \quad=$ Turbulent dissipation $\left(\mathrm{m}^{2} / \mathrm{s}^{2}\right)$ 


\section{Introduction}

Wind energy harnessing technologies are a large part of the renewable energy sector, and as such have been the focus of a great deal of research in the last couple of decades. Developing efficient and cost effective wind turbines for the urban environment is a new area of application that can further reduce dependency on fossil fuels thus reducing greenhouse gas emission. In addition, the ability to provide energy at close proximity to demand, as well as reducing the cost associated with power distribution as a result makes urban wind power a very attractive energy source. The main challenge is integrating wind turbines in complex urban builtenvironment and building aerodynamics. It is well known that wind power increases with the cube of wind velocity, i.e.

$$
P_{\text {wind }}=\frac{1}{2} \rho A U^{3}
$$

The velocity and the density of the airflow increases locally in urban areas, as air is forced to navigate around obstacles such as buildings, structures, buses and trains. This creates an opportunity to take advantage of the locally increased density and velocity of the airflow. However, the unavoidable reduction of mean flow due to the increased ground roughness (friction) and the unpredictable - and often changing - direction of air movement, i.e. wind, within urban areas result in a very turbulent flow, which leads to inefficient wind turbines. Therefore, the design of efficient and effective wind turbines, which can operate under these conditions, becomes critical for performance optimization.

\section{Overview of urban wind turbines}

The application of wind energy such as, use of wind power to sail ships and windmills goes back a long time. Persians started using windmills as early as 900 AD (Manwell et al., 2002). Figure 1 shows some ancient Persian windmills. These earliest windmills had vertical rotational axis. Horizontal axis wind mills were used in Europe in the middle ages for grinding grains and other mechanical tasks, such as pumping water (Eriksson et al., 2008). Some of the oldest designs of windmills still exist in the Netherlands today. The industrial revolution overshadowed the windmills in Europe while around the same time it became popular in the United States for water pumping applications(Abohela et al., 2013).

Since the very early attempts to generate electricity using wind by Charles Bush in the United States, 1888 (Eriksson et al., 2008), many different types of wind turbines came to existence based on aerodynamic lift and drag principles, the geometric shapes, and the rotational axis. Wind turbines are classified into horizontal axis wind turbines, HAWTs, and vertical axis wind turbines, VAWTs, based on the orientation of their rotating axis. Some examples of commercial urban wind turbines are illustrated in Figure 2 (a) for HAWTs, and Figure 2 (b) for VAWTs. The conventional horizontal wind turbines that offer a relatively more proven technology do not outperform VAWT in urban applications mainly due to the increased turbulent flow. Nevertheless, there are more options and technologies available in selecting HAWTs, and they are more economical but the synergy with the building needs to be evaluated. In built environments, wind speed and direction change frequently and the unpredictable turbulence 
makes it difficult for HAWTs to effectively harness the wind energy. HAWTs function well when the rotors are facing the wind flow. Early wind power generation in urban environment used HAWTs but the past experience has been disappointing.

The VAWTs can also be divided into two categories, lift-based VAWTs, e.g. Darrieus type, and drag-based VAWTs, e.g. Savonius type. These two wind turbines use different principles to capture wind energy. Savonius, is popular because it is reliable and easy to manufacture. The VAWTs rotate about an axis perpendicular to the wind velocity. This characteristic makes them advantageous in environments where wind direction changes frequently and the flow is turbulent. 40 years after Georges Jean Marie Darrieus patented the Darrieus wind turbine, research attention is focused on improving its performance (Macpherson, 1972, Modi et al., 1984, Newman, 1983, Shikha et al., 2005, Tabassum and Probert, 1987, Touryan et al., 1987).

HAWTs are the most common types of wind turbines. However, recent research shows that the vertical axis wind turbines are better suitable for urban applications. Based on the Wineur Project report (Cace et al., 2007), Table 1 summarizes the advantages and disadvantages of the main types of urban wind turbines.

\section{Current urban wind turbine designs}

The increasing demand for sustainable building designs and the technological advancement in wind turbine development have created an opportunity for more efficient and realistic wind turbine designs for urban applications. There are many different types of wind turbine designs today, each with a unique performance profile. Designs are driven by various requirements specific to the application and location of the device. Some of the design criteria include size constraints, noise limitations, visual disturbance concerns and low start up wind speeds. Depending on these criteria, one particular wind turbine may be more advantageous in one aspect and less in others. Savonius rotors have proven to be well suited to micro-scaled urban operations due to their simple design and relatively low cut-in wind velocity (Saha et al., 2008). The Darrieus vertical axis wind turbine (VAWT) - see Figure 3 (a) - is one of the most attractive options for rooftop installation, as it is visually unobtrusive and produces low-level acoustic emissions (Balduzzi et al., 2012).

VAWTs are known to perform well in built environments due to their multidirectional ability in turbulent flow (Elkhoury et al., 2015). Crossflex, a conceptual design of a building-integrated wind turbine using Darrieus VAWT concept was proposed to be integrated to existing buildings (Sharpe and Proven, 2010). The study tentatively validates the advantages of such a design over conventional Darrieus wind turbine in terms of its performance and usability. Further research is needed to develop this concept. A photomontage of such turbines is illustrated in Figure 3 (b).

\section{Challenges of urban wind power generation}

There have been major technological advancements in the development of large-scale wind turbines. Wind turbines in rural terrains and wind farms are presently very efficient. However, the small wind turbines used in urban applications are somewhat under researched. The urban 
built environment has a lot more restrictions for the wind turbine application than open field installations. A number of human factors, such as, clients, the public, legal and statutory bodies are critical in consideration of the urban wind power generation technologies. Most buildingmounted wind turbines in urban contexts are conventional HAWTs with rare examples of VAWTs. The inherent design of these turbines, which was originally aimed at operating in open fields, makes them less performant in site-specific applications, such as building rooftop, where wind flow characteristics can be very different (Sharpe and Proven, 2010). Turbulence and the constant change of wind direction as a result of morphological complexity of urban architectures present difficulties. The outputs of wind turbines installed on buildings have shown to be extremely low in some field experiments. The turbulence in urban environment contributes to $15 \%-30 \%$ reduction in power output according to Wineur project report (Cace et al., 2007). The average wind power is simply the time average of energy generated over a given period of operation. The capacitor factor is defined as the ratio of average power generated over an operating period to the rated peak power output. Compared to the open field wind turbines which have capacitor factor of $10 \%$, urban wind turbines' capacitor factor is only about 4 to $6.4 \%$ according to the report. The power output of wind turbines is highly unpredictable.

Considering the challenges of urban wind turbines, studies suggest specific recommendations for installation site selection and target buildings. According to the Wineur project and Warwick wind trials (2009), several requirements were found to be critical in ensuring the viability of urban wind power generation. For instance,

- Minimum average wind speed should be $5.5 \mathrm{~m} / \mathrm{s}$

- Wind turbines to be installed on a height at least $50 \%$ higher than the surrounding structures

- Wind turbines should be installed above the turbulent boundary layer with a specific vertical clearance from the rooftop

- Hub height should be at least $30 \%$ higher than the rooftop.

Abohela et al., (2013) suggests that high-rise buildings are better options when selecting buildings for wind turbine installation. The upward inclined wind flow can be exploited by installing wind turbine near the edge of the building where the turbulent layer is relatively thinner. Further studies suggested that small wind turbines should be installed on towers instead of rooftops of low-rise buildings because the wind speed amplification over the roof of such buildings is relatively lower for energy generation (Lubitz and Hakimi, 2014).

\section{Small wind turbine performance in urban application}

The general implementation of wind turbines in urban built environments is not yet very common. As a result, data available about their performance in real life applications is limited. However, there are several numerical and experimental investigations, both field and wind tunnel tests (Danao et al., 2013, Kadar, 2012, Rolland et al., 2013a, Rolland et al., 2013b, Roy and Saha, 2015). Currently, power output of urban wind turbines is low. The energy generation of several wind turbines tested for a period of 12 months on rooftops of test homes constructed in the EcoSmart show Village in Chorley, Lancashire, England were below $40 \mathrm{kWh}$ per year 
when the ratings for these turbines were in the range of $100 \mathrm{kWh}$ to $200 \mathrm{kWh}$. With the energy consumption of inverters, the wind turbines yield almost negative energy output (Glass and Levermore, 2011). This was found to be partly due to the inability of wind turbines to cope with the turbulence in urban settings. Urban wind turbines do not generate positive power at wind speed below certain level, the so-called cut-in velocity, i.e. the minimum velocity at which wind turbines start rotating to generate power. Wright and Wood, (2004) investigated the starting behavior of small HAWTs. Reliable and consistent data about urban wind turbine performance in real urban environments is still very limited. A lot of the performance data is either provided by the manufacturers or tested in optimal settings in wind tunnels or even just calculated (Grieser et al., 2015). Urban wind turbines are relatively new in the market. The commercial urban wind turbines often do not deliver their rated power output.

Larger wind turbines perform generally better (Ani et al., 2013) and have more economic efficiency. In principle, the power output of wind turbines is directly proportional to the rotor swept area. However, the experimental results from urban wind turbines show that power generated versus rotor area have almost a quadratic proportionality. Coefficient of power $\left(\mathrm{C}_{\text {power }}\right)$, sometimes referred to as coefficient of performance, is the ratio of power generated to total wind power available, i.e.

$$
C_{\text {power }}=\frac{P_{\text {generated }}}{0.5 \rho A U^{3}}
$$

This is a critical efficiency indicator. To understand the behavior of turbine at low wind speeds, field experiments were performed for six commercially available micro turbines rated between $0.6 \mathrm{~kW}$ to $5.8 \mathrm{~kW}$. Their $\mathrm{C}_{\text {power' }}$ 's are compared for a test site that has a low average wind speed of $3.7 \mathrm{~m} / \mathrm{s}$ (Ani et al., 2013). Table 2 summarizes the description of these six wind turbines. The

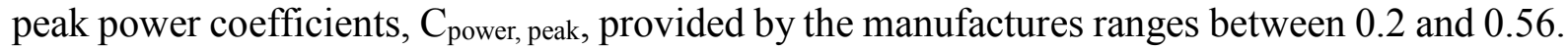
The field measurements reveal a significantly lower coefficient of power - from 0.10 to 0.30 - see Table 2 - based on annual amount of energy produced by the turbines. This behavior is quite representative of current wind turbines functioning at low wind speeds.

For a given urban application, the power coefficient is higher for HAWTs than VAWTs at higher wind speed (Eriksson et al., 2008). However, Darrieus wind turbine has a lot of potential to improve and become very efficient considering it is still relatively newer technology than HAWTs. The H-Rotor extracts more energy at lower wind speed. The $\mathrm{C}_{\text {power }}$ of Darrieus VAWT can be greatly improved by using low drag airfoils (Paraschivoiu, 2002).

Investigation of the performance of two small sized turbines, HAWT and VAWT, located at the Savona Harbor, Italy is presented by Pagnini et al, (2015). Figure 4 shows the power output measured from January to August 2012 along with the mean velocity measured by an anemometer installed nearby. Two additional anemometers were installed on the turbine structures to measure the exact wind speed experienced by the turbine blades. But the lack of accuracy of wind speed data due to the interference of wake generated by turbine blades and other wind speed recording challenges, the wind speed measured by a third anemometer that is installed nearby is used instead for reference. Initial effort was made to create $\mathrm{C}_{\text {power }}$ comparison curves for these two turbines for the consistency of this paper. But due to the challenges mentioned above, the exact results of Pagnini et al, (2015) are referenced here to avoid any confusion. It was found that both turbines were extremely sensitive to ambient turbulence 
conditions, performing well below the rated power output. HAWT is more efficient when wind blows from the sea, while VAWT performed relatively better with the wind blowing from the land, which has higher turbulence intensity. VAWT experienced much less disturbance and damage from the strong wind gusts (Pagnini et al., 2015). Neither one of these turbines are recommended for installation in complex environments at their current state.

Urban wind turbines are still at the early stages of their development. Currently, urban wind turbines are not efficient to provide a viable solution to urban energy needs. Recently, there has been significant research put into exploring the options and improving the existing designs. In fact, energy potential of urban environments is high. A recent study on wind energy potentials and small scale wind turbine performance at Incek region, Ankara, Turkey, concludes that with the recent wind turbine technologies if implemented appropriately, the entire energy need of an average household in Turkey can be met by wind energy (Bilir et al., 2015). An important development in the field of urban wind energy would be achieved if some of the recently studied designs of urban wind turbines are implemented and their performance validated with more standard experiments.

\section{Shrouded wind turbines with focus on urban applications}

To address the challenges of urban wind turbines, such as low average wind speed, turbulence and frequent change of wind direction, research has been focused on shrouded mechanisms that enclose wind turbines. Such mechanisms were found to improve the power output by either redirecting the wind flow to achieve better angle of attack and/or accelerating the wind speed.

Chong et al., (2012b) designed an Omni-Direction-Guide-Vane (ODGV) to be integrated with a VAWT for urban applications (Chong et al., 2012a, Chong et al., 2013). The guide vanes are nozzles located around the periphery of a cylindrical duct that guides the airflow towards the VAWT. Figure 5 (a) illustrates an ODGV on top of a high-rise building. The torque produced by the wind forces increases by $58 \%$ at TSR $=2.5$ and $39 \%$ at TSR $=5.1$ (Chong et al., 2013). The ODGV wind turbine also showed very good self-starting abilities. The wind tunnel experimental results show that the bare VAWT wind turbine was able to self-start at wind speed of $7.35 \mathrm{~m} / \mathrm{s}$. The same wind turbine, after the integration of ODGV, is found to self-start at 4 $\mathrm{m} / \mathrm{s}$. This addresses the previous concern about the self-starting abilities of VAWTs. This improvement on reduced cut-in wind speed also indicates longer operating hours. CFD tests have been performed and validated results obtained from the wind tunnel tests. The power output at the maximum torque with ODGV was 3.48 times higher than that of a bare turbine.

A CFD investigation of a wind and solar hybrid system that is to be installed on rooftops of buildings by B. Patankar et al., (2016) showed a power output increase of 1.7. The system not only takes advantage of the accelerated wind flow over the building but it also further accelerates and redirects the highly turbulent and otherwise slow wind speeds for wind power generation using vertical and horizontal louvers, as seen in Figure 5 (b)

A diffuser augmented wind turbine (DAWT), with a flanged brim structure at the exit periphery of the diffuser, has been tested in parks and seashores in Japan (Ohya et al., 2012, Ohya et al., 2008, Ohya and Karasudani, 2010, Wang et al., 2015). With a long diffuser length (Lt) the 
brimmed DAWT produces a power output $4 \sim 5$ times larger than that of a conventional wind turbine.

Figure 6 shows a comparison of the power output of a brimmed type of DAWT (Wind-lens) with that of a conventional wind turbine. The increase in the power output is mainly due to the increase in the mass flow rate as wind accelerates in the diffuser with the low pressure created by the vortex at the exit. The lower curve with dash line in the Figure 6 is the power curve for a conventional "bare" wind turbine. The upper power curve in solid line, obtained using wind tunnel test is for $\mathrm{C}_{\text {power }}$ value of 1.4. The power efficiency of this Wind-lense diffuser HAWT wind turbine is four times higher than that of a conventional HAWT. Skeptics argue that the power coefficient calculated using a smaller rotor blade swept area instead of the total brim area, is misleading. However, the power coefficient is still $40 \sim 70 \%$ higher for a long diffuser when calculated using the reference area $\mathrm{A}^{*}$, which refers to the exit brim diameter.

A new Building-Integrated Wind Turbine (BIWT) system directly utilizing the building skin is proposed by Park et al., (2015). The system integrates guide vanes on the vertical wall of the building to accelerate wind speed and direct it to the rotor installed inside. Figure 7 (a) shows the proposed configuration of BIWT system. One of the advantages of this system is that it can be used in addition to conventional building integrated wind turbines. Boundary layer wind tunnel test results show that the Savonius rotor inside the guide vane of the BIWT started rotating at a wind speed as low as $1.87 \mathrm{~m} / \mathrm{s}$. This is a very low cut-in wind speed compared to most wind turbines. The power coefficient at different wind speeds show a peak $\mathrm{C}_{\text {power }}$ value of 0.381 at an optimal TSR of 0.55 , which is four times better than the conventional bare Savonius rotor efficiency with peak $\mathrm{Cp}$ of 0.09 at $\mathrm{TSR}=0.5$ - according to previous experimental results from (Saha et al., 2008). Figure 7 (b) shows the power curve of a conventional Savonius turbine at $\mathrm{C}_{\text {power }}$ of 0.09 and the power curve of BIWT at $\mathrm{C}_{\text {power }}$ of 0.381 in comparison, while the experimental data of BIWT matches well with the predicted power curve.

Wind tunnel tests conducted on some other shrouded micro wind turbines also showed a significant improvement on the power coefficient. A HAWT is tested in wind tunnel with and without the addition of diffuser, and a nozzle with diffuser. A simple conical diffuser increased the $\mathrm{C}_{\text {power }}$ of the HAWT by $60 \%$. The optimal TSR is also increased by $33 \%$ with the addition of the diffuser compared to the bare wind turbine (Kosasih and Tondelli, 2012). Given that urban wind is very turbulent, concerns have been expressed about the performance of these shrouded wind turbines in urban settings. However, the experimental results show that shrouded wind turbines perform much better in highly turbulent wind. Although the increase in turbulence intensity affects the power output, the power augmentation is still achieved with the shrouds. Without the diffuser, the power generation drops significantly after TSR of 1.5 at turbulence intensity of 29\% (Kosasih and Saleh Hudin, 2016).

Krishnan and Paraschivoiu (2015) designed a new building-mounted VAWT with a diffuser shaped shroud using CFD. A diffuser shaped shroud enveloping a Savonius like wind turbine comprising a number of cylindrical cups was tested numerically. The CFD results demonstrate a $\mathrm{C}_{\text {power }}$ increase from 0.135 to 0.34 . Larin et al., (2016) investigated a horizontal axis Savonius wind turbine placed on the rooftop of a building using CFD. The horizontal axis Savonius wind turbine is dependent on the wind direction and where the turbine is placed on the rooftop as well as the shape of the building. Nevertheless, such optimized wind turbines, taking advantage of the local wind acceleration, can increase the power efficiency up to 0.24. A numerical study 
conducted by Belkacem and Paraschivoiu (2016) of an array of linear vertical axis Savonius wind turbines also shows promising results in terms of their power output. If the wind turbines are placed in an array normal to the wind direction within a 70 degrees range the power output can increase up to twofold.

\section{CFD investigation of urban flow characteristics in test sites}

Urban wind flow characteristics are highly complex compared to those in wind farms. Urban areas include structures such as buildings so the airflow faces high surface roughness affecting the wind profile significantly. With buildings obstructing the flow path at the lower atmospheric layer, rapid change of flow direction and turbulence intensity are unavoidable. This type of flow contributes to the unpredictability of wind energy in urban areas. Nevertheless, recent research suggests that urban wind energy is a great source of renewable energy though they acknowledge the difficulties associated with implementation (An-Shik Yang et al., 2016a, Morbiato et al., 2014, Toja-Silva et al., 2013). Average wind speed in a built-environment is lower than in rural areas and typical wind farms. Nevertheless, the tunneling effect created between buildings offers higher local wind speeds. Such regions include narrow gaps between tall buildings, like the Bahrain World Trade Center Towers, and the exteriors of high-rise buildings including the edge of the building rooftops. Therefore, the analysis of wind in complex terrains is important for micro-siting of wind turbines (Ledo et al., 2011). One of the main difficulties in deployment of urban wind turbines is the lack of means to accurately predict wind energy potential (AnShik Yang et al., 2016b). Determining flow field is essential in assessing wind power. Different methods such as Weibull analysis, micrometeorology data, experimental measurement and computational fluid dynamics (CFD) were used to evaluate availability of wind energy for power generation (Chandel et al., 2014, Mertens, 2002). Field measurements and wind tunnel experiments are traditionally the most reliable in such analysis. However, in field measurements as well as in wind tunnel tests only point measurements are performed in selected areas, thus making it great for macro-siting of wind turbines such as wind farms. But for micro-siting of wind turbines, these measurements are not as convenient. Techniques such as Particle Image Velocimetry (PIV) and Laser-Induced Florescenes (LIF) can provide scan data of 2D or in some cases 3D wind flow profile, but they are very expensive and difficult to perform (Blocken, 2015). Numerical modeling of wind flow in built areas using CFD is a great alternative. With the current day advancement of computing technologies and commercial software, CFD can perform such wind studies much faster and provide greater details at high resolution facilitating the micro-siting of small urban wind turbines. Miller et al., (2013) argues that CFD can provide a good picture of wind characteristics and can be used as a reliable tool in evaluating specific sites. A study conducted by Prospathopoulos et al., (2012) compared results from 3D RANS solver with experimental data. Results show that CFD predicts wind profile in complex terrain accurately except in steep terrains, such as cliffs.

Based on the great number of articles on CFD implementation in urban wind engineering as well as following the specific guidelines and the best practices of modeling atmospheric boundary layer flows in urban environments by Blocken et al., 2004, Blocken and Carmeliet, 2004, Blocken et al., 2007, Blocken et al., 2011, Blocken, 2015, Franke et al., 2011 and Toparlar 
et al., 2015, CFD tests are performed to improve the deployment of rooftop-mounted urban wind turbines by introducing an external turbine casing mechanism - a diffuser shroud, on the rooftop of a test building, for its ability to utilize the incoming flow over the edge of a building rooftop. The diffuser shroud, a fluid machine, sitting on the roof of a tall building, guides the upward climbing airflow and further accelerates the flow inside the diffuser where a small turbine can be installed to harness the wind energy. First, some wind analysis using CFD is done on two test sites to characterize the urban wind flow and to select a siting location for the diffuser. In the second stage, a CFD model of the diffuser on a hypothetical single building is created for geometric analysis and the optimization of the diffuser. Then with the optimized diffuser shroud modeled on the roof of a selected building in the previous test site, more CFD is performed to show the diffuser's efficiency as a proof of concept.

\subsection{Wind flow characterization in a test site}

Having to navigate around urban structures such as buildings, wind flow loses much of its power making it difficult to harness useful wind energy. However, careful investigation of wind flow profile over the building rooftop brought to attention the possibilities of taking advantage of such flow patterns. Two different urban test sites, one in the Cote-des-Neiges borough of Montreal, located in a residential area with dense urban structures, such as apartment buildings and trees (1) and another in Pointe-Claire, Quebec, a commercial area with shopping malls and big open parking lots around the core domain (2) - see Figure 8.

CFD simulation was performed for eight different wind directions with the azimuthal increment angle of 45 degrees in both test sites. For consistency, only one mesh is created for the test site for all wind directions. The area of interest or the core domain is an approximately rectangular area, 500 meters each side. The core domain is extended and an octagonal prismed domain with lateral eight sides is created with 500 meters height from the ground and 2000 meters from the inlet to the outlet - see Figure 9 (a). This will allow the core domain to have $15 \mathrm{H}$ downstream and $10 \mathrm{H}$ in height. $\mathrm{H}$ is approximately the height of the tallest building in the area of interest. Three of the eight sides are used as velocity inlet with boundary conditions defined by equations 7.4 to 7.6, and opposite three sides as pressure outlet in each one of the eight wind direction cases, while the remaining two sides and the top are modelled as symmetric boundary condition. Figure 9 (b) shows the velocity profile at the domain inlet. The $u_{A B L}^{*}$ is the ABL friction velocity used to determine turbulent kinetic energy, $\mathrm{k}$ and the turbulent dissipation, $\varepsilon$. $\mathrm{K}$ is the von Karman constant and $\mathrm{C}_{\mathrm{u}}$ is a model constant of the turbulence model. The $\mathrm{z}$ is the domain $\mathrm{z}$ coordinate representing the vertical elevation. The core domain geometric details are explicitly modeled and the outside of the core domain such as upstream, sides, and the downstream sections are implicitly modeled using aerodynamic roughness $z_{0}$ and the roughness height $\mathrm{k}_{\mathrm{SABL}}$ to account for the roads, buildings, and the vegetation outside of the core domain. The relationship between $z_{0}$ and $\mathrm{k}_{\mathrm{s}, \mathrm{ABL}}$ are shown in equation 7.3 and incorporated into the solution process. Realizable k- $\varepsilon$ turbulence modelling has demonstrated superior performance for simulation that involves flow separation, vortex eddies and recirculation (Karava et al., 2011). Standard incompressible Navier-Stokes equations 7.1 and 7.2 with Ansys FLUENT 3D steady state model are used with the Realizable k- $\varepsilon$ turbulence modelling. Unstructured mesh with fine inflation layers, 5 layers within the 2 meters height, on the ground is created. 


$$
\begin{gathered}
\nabla \cdot \vec{u}=0 \\
\rho \frac{\partial \vec{u}}{\partial t}+\rho(\vec{u} \cdot \nabla) \vec{u}=-\nabla p+\mu \nabla^{2} \vec{u}+f
\end{gathered}
$$

where $\overrightarrow{\mathrm{u}}$ is the velocity vector, $\mu$ is dynamic viscosity and $\mathrm{f}$ is body forces,

$$
\begin{aligned}
& k_{S, A B L}=\frac{9.793 z_{0}}{C_{S}} \\
& U_{A B L}=\frac{u_{A B L}^{*}}{K} \operatorname{In}\left(\frac{z+z_{0}}{z_{0}}\right) \\
& k=\frac{\left(u_{A B L}^{*}\right)^{2}}{\sqrt{C_{u}}} \\
& \varepsilon=\frac{\left(u_{A B L}^{*}\right)^{3}}{K\left(z+z_{0}\right)}
\end{aligned}
$$

\subsection{Summary of findings from test sites}

The preliminary CFD analysis shows that the wind profile is very complex in built environment like the test sites. Figure 10 (a) shows the velocity streamlines of the flow in the test site (1), in which, the local flow profile changes significantly with each different wind direction and the flow is highly turbulent due to dense topographical structures. The mean wind speed is very low for power generation. There are large vortices in between buildings that may affect the stability of any local flow acceleration such as flow over the roof. There are buildings with different shapes and roofs. The building geometry and the roof shape also play an important role in shaping the urban wind flow. Complexity of the flow pattern and the turbulence is more forgiving in test site (2) with large open areas such as grass and parking lots near the area of interest. Some of the important factors to consider when selecting a turbine site are:

- Wind direction with respect to the building geometry;

- Building height in relation to surrounding structures;

- Spacing of the buildings ;

- Upstream topography and its effect on the ABL profile;

- Shape of the buildings and the roofs.

Similar to the flow pattern shown in Figure 10 (b), velocity vector of the flow upstream of a building in test site (2), Figure 10 (c) shows a smoke visualization of airflow over two buildings in wind tunnel from an ABL flow study done by Blocken and Carmeliet, (2004). When the surrounding buildings are relatively lower and certain distance apart, upper flow layer climbs upward as it approaches tall buildings and accelerates. The upward flow is dependent on the flow direction with respect to the roof and flows higher over the rooftop. The CFD results in the test site also predict similar pattern. Wineur project and Warwick wind trials (2009) recommend that any roof-mounted wind turbine should be installed at a location $30 \%$ higher of the building height because of the turbulence region at the lower level of the flow over the roof. If the upward airflow can be guided, the acceleration can be beneficial for power generation; and perhaps the costs and complications associated with installing large turbine towers on the rooftops can be avoided. 


\section{Flanged diffuser shroud mechanism for roof-mounted wind turbines}

Previous research demonstrated that a diffuser shroud casing around wind turbines can accelerate wind speed thus increasing wind power (Ohya et al., 2012, Ohya et al., 2008, Ohya and Karasudani, 2010, Wang et al., 2015). A diffuser shroud mechanism - see Figure 11 (a) - is proposed to be installed on building rooftops to channel the upward climbing wind flow and potentially accelerate the flow speed for power generation. Oyha et al. (2010) proposed a similar shroud casing - a fluid machine, that basically consists of a conical diffuser at the core, flow streamlining cycloidal curve geometry at the inlet shroud, and a flange at the exist periphery. Several variations of the geometries have been tested and a compact version of such shroud casing has been patented (Patent number: US 8834092 B2). The flow separation downstream is achieved using a non-streamlining flange at the exit periphery to create annular Karman vortex streets. The low pressure created downstream by the vortices increase the speed of the internal flow. Inspired by Ohya et al.'s work, a series of parametric studies of the diffuser shroud geometry and CFD optimization resulted in a geometry that not only guides the airflow but also accelerates the flow speed inside the casing. Figure 11 (a) and (b) show velocity streamlines at the diffuser from a perspective view and on symmetry cut-plane. Instead of the conical diffuser of Ohya et al.'s design, this rooftop shroud casing has a rectangular flow section. Figure 12 (a) shows a photomontage of the diffuser with a hypothetical wind turbine inside while Figure 12 (b) shows the CFD velocity streamlines at the symmetric vertical mid plane.

\subsection{CFD results}

In the preliminary stage of the parametric design optimization and CFD validation, only half of the domain that includes a diffuser on the roof of a single hypothetical building with dimensions of $16 \mathrm{~m} \times 16 \mathrm{~m} \times 28.45 \mathrm{~m}(\mathrm{~W} \times \mathrm{L} \times \mathrm{H})$ is analysed to reduce computational cost. CFD models with different mesh sizes and different turbulence models are tested to validate the CFD results numerically. Figure 13 (a) illustrates the computational domain with dimensions and the boundary conditions. The CFD tests are performed using Realizable $k-\varepsilon$ and $k-\omega$ SST model for comparison. Figure 13 (b) shows the fine mesh used for the diffuser on top of the building and Figure 13 (c) shows the fine inflation layers used to satisfy the $y+$ of 1 requirement for $k-\omega$ SST turbulence model.

Flow profile and velocity magnification factor, the ratio of mean velocity at the throat of the diffuser to the velocity upstream at the same height, is compared in different cases. Two different models using different mesh sizes predicted very similar velocity magnification factors at the throat of the diffuser with a difference of $3.3 \%$. The $k-\omega$ SST and Realizable $k-\varepsilon$ turbulence models predicted very similar flow patterns and the velocity magnification factor differs by $2.1 \%$. Like Realizable $k-\varepsilon$ turbulence model, $k-\omega$ SST model is known for its advantages to more accurately capture flow that involves high pressure gradient and eddies.

\subsection{Wind tunnel test challenges: Reynolds number and geometric scales}

Wind tunnel tests are important to validate the performance of the diffuser predicted by numerical analysis such as CFD. Unfortunately, a wind tunnel test has challenges associated with one, Reynolds number in the case of curved surfaces and two, geometric scales. 
Reynolds number similarity is very important but it is not achievable in a ABL wind tunnel with scaled down geometric models. Reynolds number is the ratio of inertial forces to viscous forces and it is defined as,

$$
R e=\frac{U L}{v}
$$

where:

- $L$ is a characteristic linear dimension $(\mathrm{m})$

- $U$ is the velocity of the fluid with respect to the object $(\mathrm{m} / \mathrm{s})$

- $\quad v$ is the kinematic viscosity of the fluid $\left(\mathrm{m}^{2} / \mathrm{s}\right)$

It is possible to simulate a full-scale wind profile in the analysis of buildings in ABL wind tunnels by using sharp building edges and corners thus circumventing the Reynolds number similarity condition. However, the sensitivity of the flow pattern inside the diffuser with respect to the Reynolds number is more significant. CFD investigation of the effect of Reynolds number with different geometric scales shows that at the smaller geometric size or lower Reynolds number for that matter, the flow separates as it goes around the convex part of the bottom diffuser shroud - see Figure 14. With the full scale at $\mathrm{Re}=17$ million the flow pattern is ideal for diffuser performance - see Figure 14 (c). As the Reynolds number decreases, the flow starts to separate at the bottom shroud - see Figure (b). At the 1:100 scale or Re $=170000$, the flow separates almost immediately after the entrance - see Figure 14 (a). This can be explained by the prevailing viscous forces at the lower Reynolds number creating severe adverse pressure gradient at the curvature of the bottom shroud as flow "turns" around the surface, resulting in flow separation.

The wind tunnel test validation is difficult due to the Re effects that are significant. However, the CFD methodology has been verified with other research which has been validated using large wind tunnel or field test measurements. It has also been numerically validated against mesh and turbulence model sensitivity. Figure 10 (b) and (c) show at least the qualitative similarity of flow patterns around buildings between CFD and wind tunnel. Further wind tunnel or field tests are necessary to gain more confidence in the results obtained by CFD. But the CFD results can be used as a proof of concept for the performance of the diffuser mechanism.

\subsection{Characteristics of flanged diffuser shroud}

CFD tests with the ABL flow conditions show that at the throat of the diffuser, the wind velocity can accelerate up to 1.6 times of the upstream velocity at the same height. This increase in velocity indicates that using such mechanisms, the wind power can be significantly increased, as much as four times compared the power of a conventional wind turbine installed on a turbine tower of the same height. This also helps turbines operate for longer hours by easing the limitation of low cut-in speed. The flanges at the exit of the shroud, like Ohya et al.'s power augmentation method, draw more air into the diffuser by creating suction downstream. The cycloidal curves used at the entrance on both upper and lower shrouds improve the streamlining and guide the flow towards the diffuser throat where the turbine should be installed. In addition to its ability to guide and accelerate the airflow, the diffuser mechanism addresses some of the common problems urban wind turbines have and offers advantages such as, 
- Increased safety reducing contact between rotating turbine blades and the external objects, debris and animals

- Containing broken pieces of turbine blades from shooting out to public areas in case of damage

- Reducing noise from the turbine blades as fluctuating vortices generated by the blades are suppressed within the boundary layer on the internal shroud surfaces

- Eliminating visual disturbances as the moving parts of the turbine are hidden inside the solid casing

- Providing potential surfaces for solar panels or similar hybrid power systems

- Providing a braking mechanism by closing the inflow.

\section{Diffuser modeling in the test site}

One of the challenges and skepticism of optimization is that the performance improvement may be dependent on the setup of the diffuser including its location, as it is specific to local flow characteristics. So before going into too much fine-tuning, it is important to verify the performance of the diffuser in an existing urban structure. A CFD analysis is carried out to test the mechanism on a rooftop of an existing building in the test site to further verify its performance promised by previous CFD optimization. Wind roses with wind statistics of Montreal including dominant wind directions are used as input for the boundary conditions of CFD setup following the best practices recommended by Blocken (2015). Based on the statistical dominant wind direction, westerly wind, and the topographical characteristics, such as, being the tallest building with less dense structures in the immediate surrounding and one of the building sides facing directly west, the building encircled in yellow - see Figure 15 - in test site (2) is chosen as the test building. Figure 16 (a) shows the CFD model of the building with the diffuser modeled on the rooftop and (b) the google earth view of the location.

The CFD result of the test site agrees well with the prediction of the design stage CFD for performance of the diffuser. The test site CFD shows that the velocity is magnified by 1.52 times at the throat of the diffuser. This is very close to the result of 1.6 predicted by the optimized, numerically validated CFD earlier in the design stage - see Figure 11 (b) and 14 (c). The velocity is calculated as the mass flow average at the diffuser throat and compared to the velocity upstream at the same height. Figure 16 shows (a) velocity contours at the cut plane of the diffuser and (b) velocity streamlines at the selected building with the diffuser on top. The flow coming from west (left in Figure 16) approaches the building and the upper flow layer moves upward over the edge. This airflow is drawn into the diffuser with the suction created by the flange at the outlet, sharply bending the flow direction. The flow pattern near the selected building without the diffuser - see Figure 10 (b) - is similar to that in the model with the diffuser - see Figure 16 (b). The streamlines shown in red - see Figure 16 (b) - at the diffuser inlet indicates that the flow accelerates going into the diffuser. The diffuser on the test building effectively takes advantage of the local flow acceleration as predicted in the design stage. 


\section{Conclusion}

The scarcity of experimental data of wind turbines installed in urban settings makes it harder to compare turbine efficiencies and the viability of different wind turbines available today. Conventional wind turbines directly located in urban built-environment do not perform well. Some wind turbines, especially VAWTs, still show good results but should be further optimized for urban applications. Site-specific wind profile analysis together with rooftop turbulence assessment can improve the efficiency of current urban wind turbine designs. Power augmentation concepts using diffuser and shrouded brims around conventional wind turbines promise significant power coefficient increase. The flanged diffuser shroud mechanism can redirect the airflow over building rooftop towards the wind turbine installed inside of the diffuser casing as well as can accelerate the flow thus augmenting wind power. The concept is validated in a real urban test site with real wind data using CFD. Wind tunnel tests and field measurements in the future would be useful to validate of the preliminary CFD results. Exploiting shrouded power augmentation technologies and proper synergistic design of turbines and buildings, urban wind power extraction can become an important part of renewable energy source. Urban wind turbine technology is still at its early state and there is a lot of space to improve- promising directions have already been identified. There are still a lot of questions about the performance of wind turbines and its economics but continuous research in this area will provide some of the much-needed answers.

\section{ACKNOWLEDGEMENTS}

This work was supported by funds originated from the Concordia Institute for Water, Energy and Sustainable Systems (CIWESS). Access to Concordia atmospheric boundary layer wind tunnel was essential and it is greatly appreciated. 


\section{REFERENCES}

Abohela, I., Hamza, N., Dudek, S. 2013. Effect of roof shape, wind direction, building height and urban configuration on the energy yield and positioning of roof mounted wind turbines. Renewable Energy 50, 1106-18.

Ani, S.O., Polinder, H., Ferreira, J.A. 2013. Comparison of Energy Yield of Small Wind Turbines in Low Wind Speed Areas. IEEE Transactions on Sustainable Energy 4, 42-9.

An-Shik Yang, Ying-Ming Su, Chih-Yung Wen, Yu-Hsuan Juan, Wei-Siang Wang, ChiangHo Cheng. 2016. Estimation of wind power generation in dense urban area. Applied Energy 171, 213-30.

Balduzzi, F., Bianchini, A., Carnevale, E.A., Ferrari, L., Magnani, S. 2012. Feasibility analysis of a Darrieus vertical-axis wind turbine installation in the rooftop of a building. Applied Energy 97, 921-929.

Belkacem, B., Paraschivoiu, M. 2016. CFD Analysis of a Finite Linear Array of Savonius Wind Turbines 753.

Bilir, L., Imir, M., Devrim, Y., Albostan, A. 2015. An investigation on wind energy potential and small scale wind turbine performance at Incek region - Ankara, Turkey. Energy Conversion and Management 103, 910-23.

Blocken, B., Roels, S., Carmeliet, J. 2004. Modification of pedestrian wind comfort in the Silvertop Tower passages by an automatic control system. Journal of Wind Engineering and Industrial Aerodynamics 92, 849-73.

Blocken, B. 2015. Computational Fluid Dynamics for urban physics: Importance, scales, possibilities, limitations and ten tips and tricks towards accurate and reliable simulations. Building and Environment 91, 219-245.

Blocken, B., Carmeliet, J. 2004. Pedestrian wind environment around buildings: Literature review and practical examples. Journal of Thermal Envelope and Building Science 28, 107 159.

Blocken, B., Stathopoulos, T., Carmeliet, J. 2007. CFD simulation of the atmospheric boundary layer: wall function problems. Atmospheric Environment 41, 238-252.

Blocken, B., Stathopoulos, T., Carmeliet, J., Hensen, J.L.M. 2011. Application of computational fluid dynamics in building performance simulation for the outdoor environment: An overview. Journal of Building Performance Simulation 4, 157-184.

Cace, J., Horst, E., Syngellakis, K., Niel, M., Clement, P., Heppener, R., Peirano, E. 2007. Urban Wind Turbines, Guidelines for small wind turbines in the built environment 2016, 41. 
Chandel, S.S., Ramasamy, P., Murthy, K.S.R. 2014. Wind power potential assessment of 12 locations in western Himalayan region of India. Renewable and Sustainable Energy Reviews $39,530-545$.

Chong, W.T., Fazlizan, A., Poh, S.C., Pan, K.C., Hew, W.P., Hsiao, F.B. 2013. The design, simulation and testing of an urban vertical axis wind turbine with the omni-direction-guidevane. Applied Energy 112, 601-609.

Chong, W.T., Poh, S.C., Fazlizan, A., Pan, K.C. 2012a. Vertical axis wind turbine with omnidirectional-guide-vane for urban high-rise buildings. Journal of Central South University of Technology 19, 727-32.

Chong, W.T., Fazlizan, A., Pan, K.C., Poh, S.C. 2012b. Design and wind tunnel testing of a Savonius wind turbine integrated with the omni-direction-guide-vane 1, 211-217.

D'Ambrosio, M., Medaglia, M. 2010. Vertical Axis Wind Turbines: History, Technology and Applications.

Danao, L.A., Eboibi, O., Howell, R. 2013. An experimental investigation into the influence of unsteady wind on the performance of a vertical axis wind turbine. Applied Energy 107, 403411.

Encraft Warwick Wind Trials Final Report2009. 2016, 64.

Elkhoury, M., Kiwata, T., Aoun, E. 2015. Experimental and numerical investigation of a three-dimensional vertical-axis wind turbine with variable-pitch. Journal of Wind Engineering \& Industrial Aerodynamics 139, 111-23.

Eriksson, S., Bernhoff, H., Leijon, M. 2008. Evaluation of different turbine concepts for wind power. Renewable and Sustainable Energy Reviews 12, 1419-1434.

Franke, J., Hellsten, A., Schlunzen, K.H., Carissimo, B. 2011. The COST 732 Best Practice Guideline for CFD simulation of flows in the urban environment: A summary. International Journal of Environment and Pollution 44, 419-427.

Glass, A., Levermore, G. 2011. Micro wind turbine performance under real weather conditions in urban environment. Building Services Engineering Research \& Technology 32, 245-62.

Grieser, B., Sunak, Y., Madlener, R. 2015. Economics of small wind turbines in urban settings: an empirical investigation for Germany. Renewable Energy 78, 334-50.

Kadar, P. 2012. Comparative performance analysis of small scale wind turbines. Journal of Engineering Science and Technology Review 5, 42-47. 
Karava, P., Jubayer, C.M., Savory, E. 2011. Numerical modelling of forced convective heat transfer from the inclined windward roof of an isolated low-rise building with application to photovoltaic/thermal systems. Applied Thermal Engineering 31, 1950-1963.

Kosasih, B., Saleh Hudin, H. 2016. Influence of inflow turbulence intensity on the performance of bare and diffuser-augmented micro wind turbine model. Renewable Energy 87, 154-167.

Kosasih, B., Tondelli, A. 2012. Experimental Study of Shrouded Micro-Wind Turbine. Procedia Engineering 49, 92-98.

Krishnan, A., Paraschivoiu, M. 3D analysis of building mounted VAWT with diffuser shaped shroud. Sustainable Cities and Society.

Larin, P., Paraschivoiu, M., Aygun, C. 2016. CFD based synergistic analysis of wind turbines for roof mounted integration. Journal of Wind Engineering \& Industrial Aerodynamics 156, $1-13$.

Ledo, L., Kosasih, P.B., Cooper, P. 2011. Roof mounting site analysis for micro-wind turbines. Renewable Energy 36, 1379-91.

Lubitz, D., Hakimi, R. 2014. Wind environment at a roof-mounted wind turbine on a peaked roof building. International Journal of Sustainable Energy 35, 172-189.

Macpherson, R.B. 1972. Development and Testing of Low-head High-Efficiency Kinetic Energy Machines -An Alternative for the Future.

Manwell, J.F., Mcgowan, J.G., Roger, A.L. 2002. Wind Energy Explained: Theory, Design and Application. John Wiley and Sons Ltd, Chichester, United Kingdom.

Mertens, S. 2002. Wind energy in urban areas: Concentrator effects for wind turbines close to buildings. Refocus 3, 22-24.

Miller, A., Chang, B., Issa, R., Chen, G. 2013. Review of computer-aided numerical simulation in wind energy. Renewable and Sustainable Energy Reviews 25, 122-34.

Modi, V.J., Roth, N.J., Fernando, M.S.U.K. 1984. Optimum-configuration studies and prototype design of a wind-energy-operated irrigation system. Journal of Wind Engineering and Industrial Aerodynamics 16, 85-96.

Morbiato, T., Borri, C., Vitaliani, R. 2014. Wind energy harvesting from transport systems: A resource estimation assessment. Applied Energy 133, 152-68.

Newman, B.G. 1983. ACTUATOR-DISC THEORY FOR VERTICAL-AXIS WIND TURBINES. Journal of Wind Engineering and Industrial Aerodynamics 15, 347-355. 
Ohya, Y., Uchida, T., Karasudani, T., Hasegawa, M., Kume, H. 2012. Numerical studies of flow around a wind turbine equipped with a flanged-diffuser shroud using an actuator-disk model. Wind Engineering 36, 455-72.

Ohya, Y., Karasudani, T. 2010. A shrouded wind turbine generating high output power with wind-lens technology. Energies 3, 634-649.

Ohya, Y., Karasudani, T., Sakurai, A., Abe, K., Inoue, M. 2008. Development of a shrouded wind turbine with a flanged diffuser. Journal of Wind Engineering and Industrial Aerodynamics 96, 524-539.

Pagnini, L.C., Burlando, M., Repetto, M.P. 2015. Experimental power curve of small-size wind turbines in turbulent urban environment. Applied Energy 154, 112-21.

Paraschivoiu, I. 2002. Wind turbine design with emphasis on Darrieus concept. Polytechnic International Press, Canada.

Park, J., Jung, H., Lee, S., Park, J. 2015. A new building-integrated wind turbine system utilizing the building. Energies 8, 11846-11870.

Patankar, B., Tyagi, R., Kiss, D., Suma, A.B. 2016. Evaluation of an Integrated Roof Wind Energy System for urban environments. Journal of Physics: Conference Series 753, 102007 (11 pp.).

Prospathopoulos, J.M., Politis, E.S., Chaviaropoulos, P.K. 2012. Application of a 3D RANS solver on the complex hill of Bolund and assessment of the wind flow predictions. Journal of Wind Engineering and Industrial Aerodynamics 107-108, 149-59.

Rolland, S., Newton, W., Williams, A.J., Croft, T.N., Gethin, D.T., Cross, M. 2013a.

Simulations technique for the design of a vertical axis wind turbine device with experimental validation. Applied Energy 111, 1195-203.

Rolland, S.A., Thatcher, M., Newton, W., Williams, A.J., Croft, T.N., Gethin, D.T., Cross, M. 2013b. Benchmark experiments for simulations of a vertical axis wind turbine. Applied Energy 111, 1183-1194.

Roy, S., Saha, U.K. 2015. Wind tunnel experiments of a newly developed two-bladed Savonius-style wind turbine. Applied Energy 137, 117-125.

Saha, U.K., Thotla, S., Maity, D. 2008. Optimum design configuration of Savonius rotor through wind tunnel experiments. Journal of Wind Engineering and Industrial Aerodynamics 96, 1359-1375.

Sharpe, T., Proven, G. 2010. Crossflex: Concept and early development of a true building integrated wind turbine. Energy and Buildings 42, 2365-2375. 
Shikha, Bhatti, T.S., Kothari, D.P. 2005. Early development of modern vertical and horizontal axis wind turbines: a review. Wind Engineering 29, 287-99.

Stathopoulos, T., Surry, D. 1983. SCALE EFFECTS IN WIND TUNNEL TESTING OF LOW BUILDINGS. Journal of Wind Engineering and Industrial Aerodynamics 13, 313-326.

Tabassum, S.A., Probert, S.D. 1987. VERTICAL-AXIS WIND TURBINE: A MODIFIED DESIGN. Applied Energy 28, 59-67.

Toja-Silva, F., Colmenar-Santos, A., Castro-Gil, M. 2013. Urban wind energy exploitation systems: Behaviour under multidirectional flow conditions-Opportunities and challenges. Renewable and Sustainable Energy Reviews 24, 364-78.

Toparlar, Y., Blocken, B., Vos, P., Van Heijst, G.J.F., Janssen, W.D., van Hooff, T., Montazeri, H., Timmermans, H.J.P. 2015. CFD simulation and validation of urban microclimate: A case study for Bergpolder Zuid, Rotterdam. Building and Environment 83, 79-90.

Touryan, K.J., Strickland, J.H., Berg, D.E. 1987. ELECTRIC POWER FROM VERTICALAXIS WIND TURBINES. Journal of Propulsion and Power 3, 481-493.

Wang, W., Matsubara, T., Hu, J., Odahara, S., Nagai, T., Karasutani, T., Ohya, Y. 2015. Experimental investigation into the influence of the flanged diffuser on the dynamic behavior of CFRP blade of a shrouded wind turbine. Renewable Energy 78, 386-397.

Wright, A.K., Wood, D.H. 2004. The starting and low wind speed behaviour of a small horizontal axis wind turbine. Journal of Wind Engineering and Industrial Aerodynamics 92, 1265-1279. 
WIND TURBINE DESIGNS FOR URBAN APPLICATIONS:

A CASE STUDY OF SHROUDED DIFFUSER CASING FOR TURBINES

(Figures)

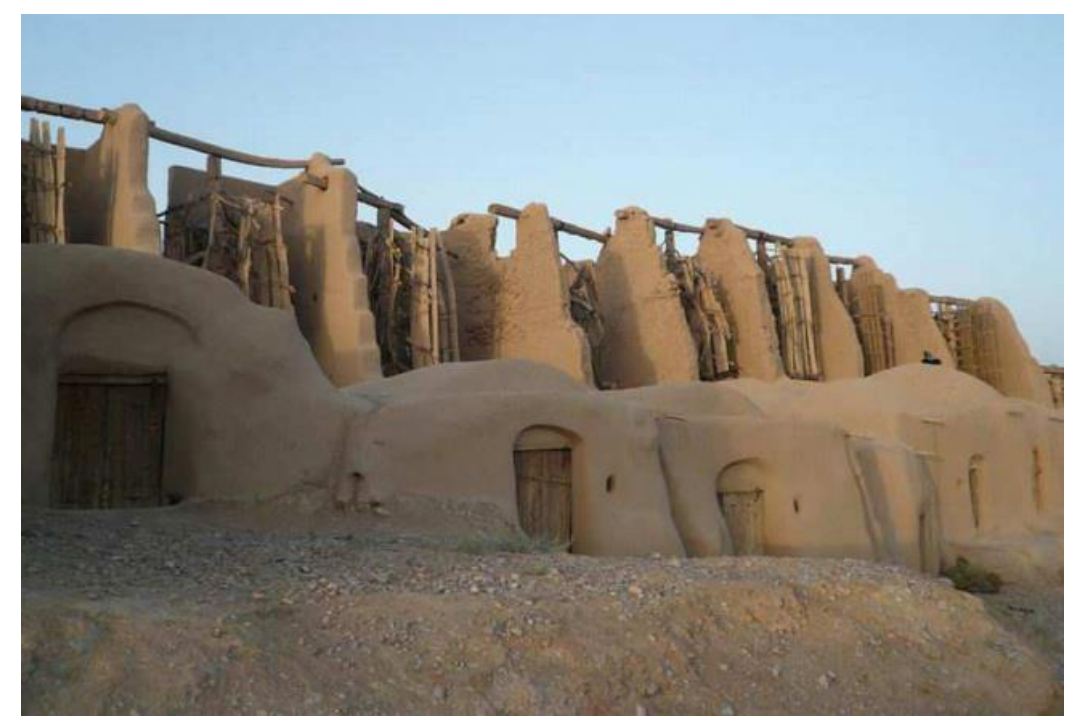

Figure 1 Persian Windmills (D'Ambrosio and Medaglia, 2010) 


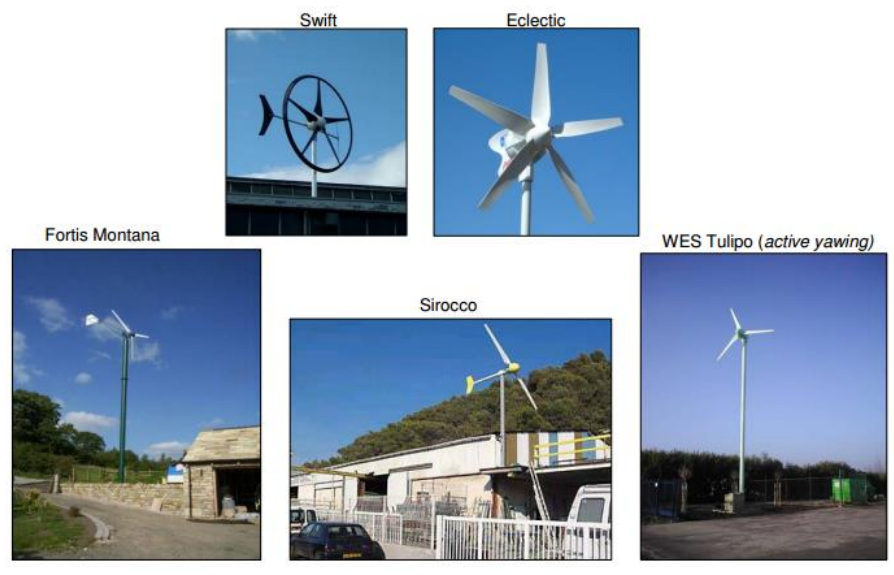

a)
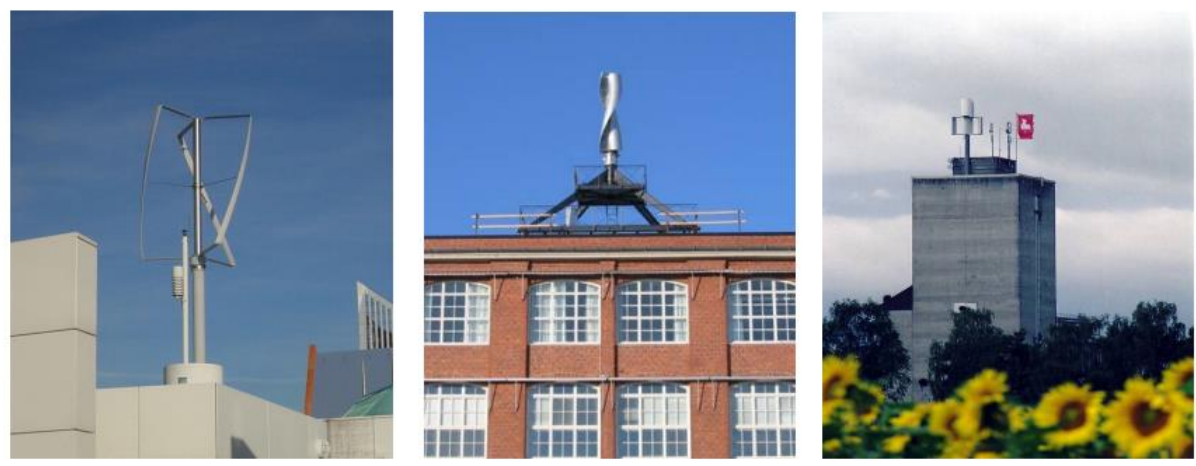

b)

Figure 2 Some examples of commercial a) HAWTs and b) VAWT (Cace et al., 2007) 


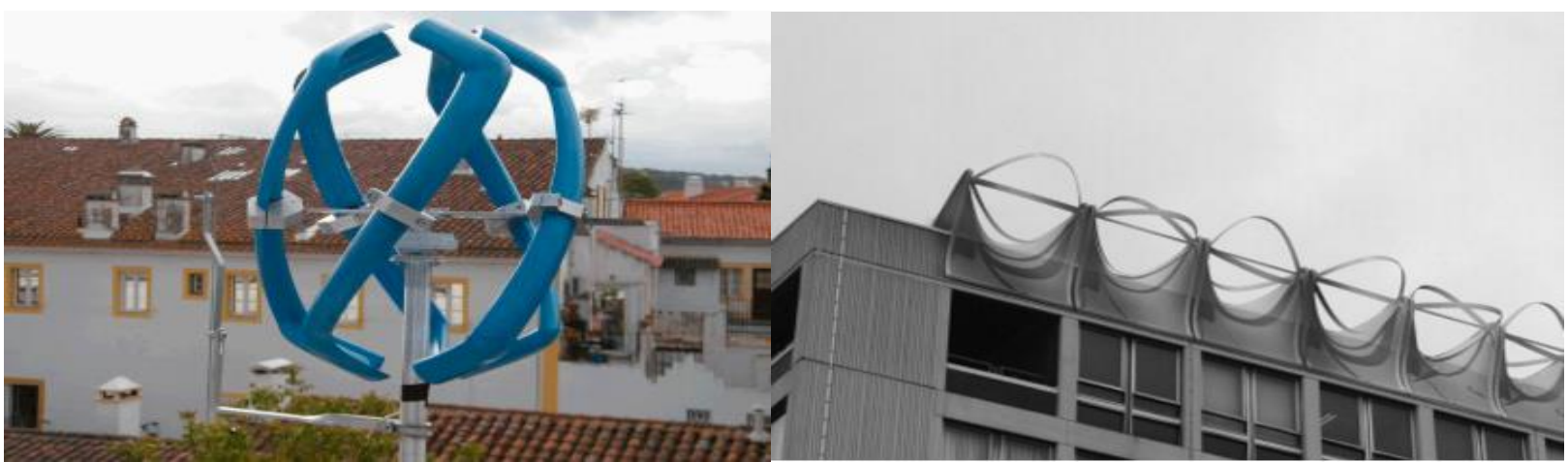

a)

b)

Figure 3 a) Photomontage of Cross Flex building integrated wind turbines (Sharpe and Proven, 2010a) b) New Darrieus VAWT design prototype (Balduzzi et al., 2012) 


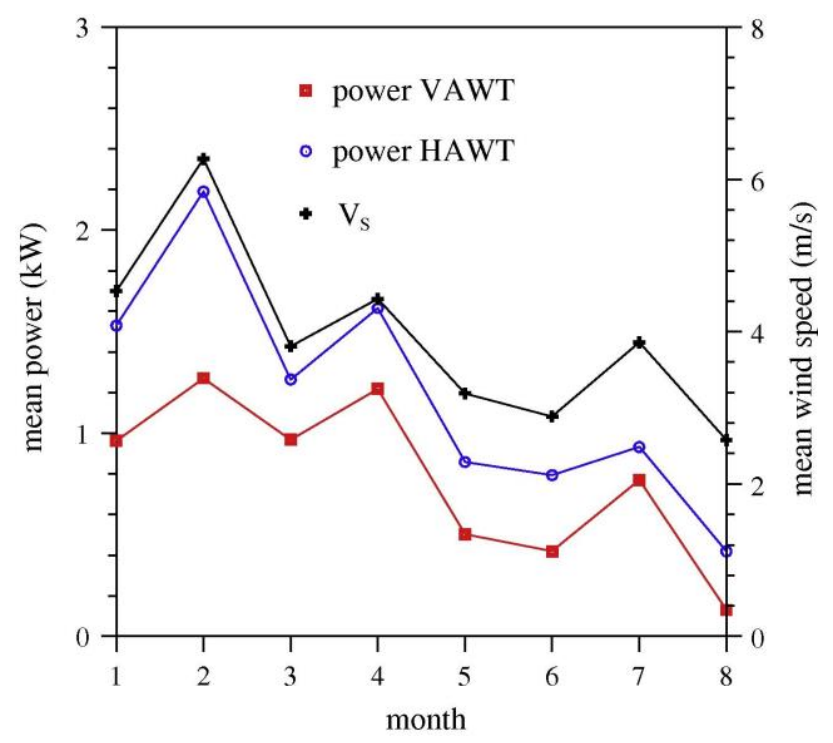

Figure 4 Monthly-averaged power output of two wind turbines (Pagnini et al., 2015) 

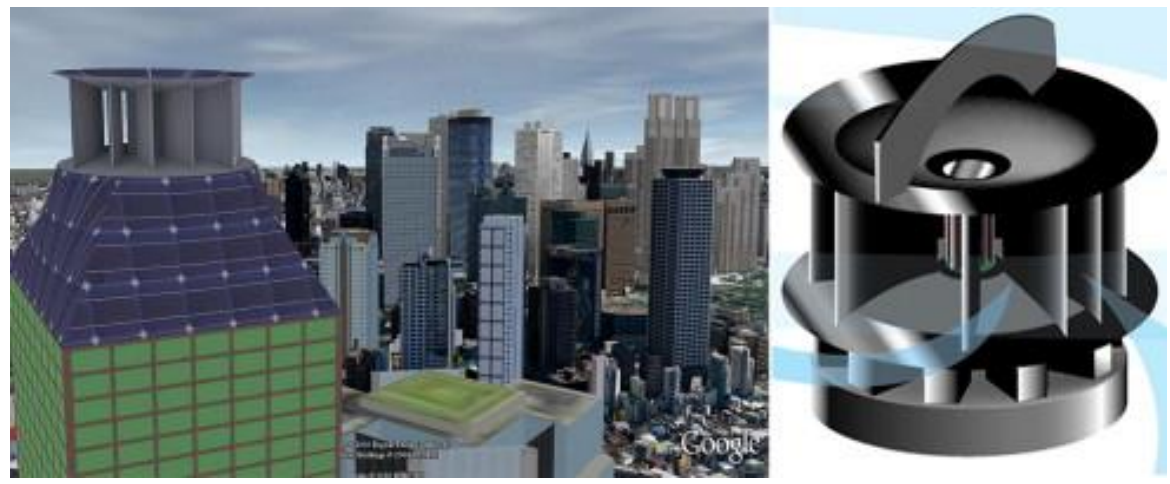

a)

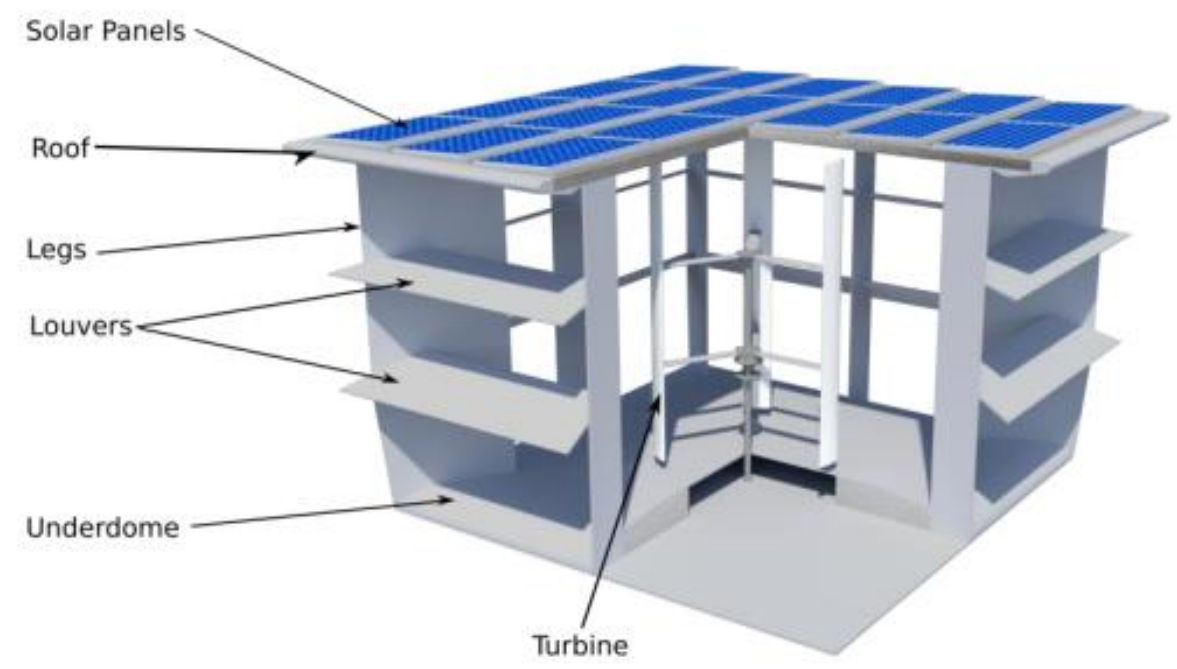

b)

Figure 5 (a) ODGV wind turbine (Chong et al., 2012), (b) PowerNEST concept (Patankar et al., 2016) 


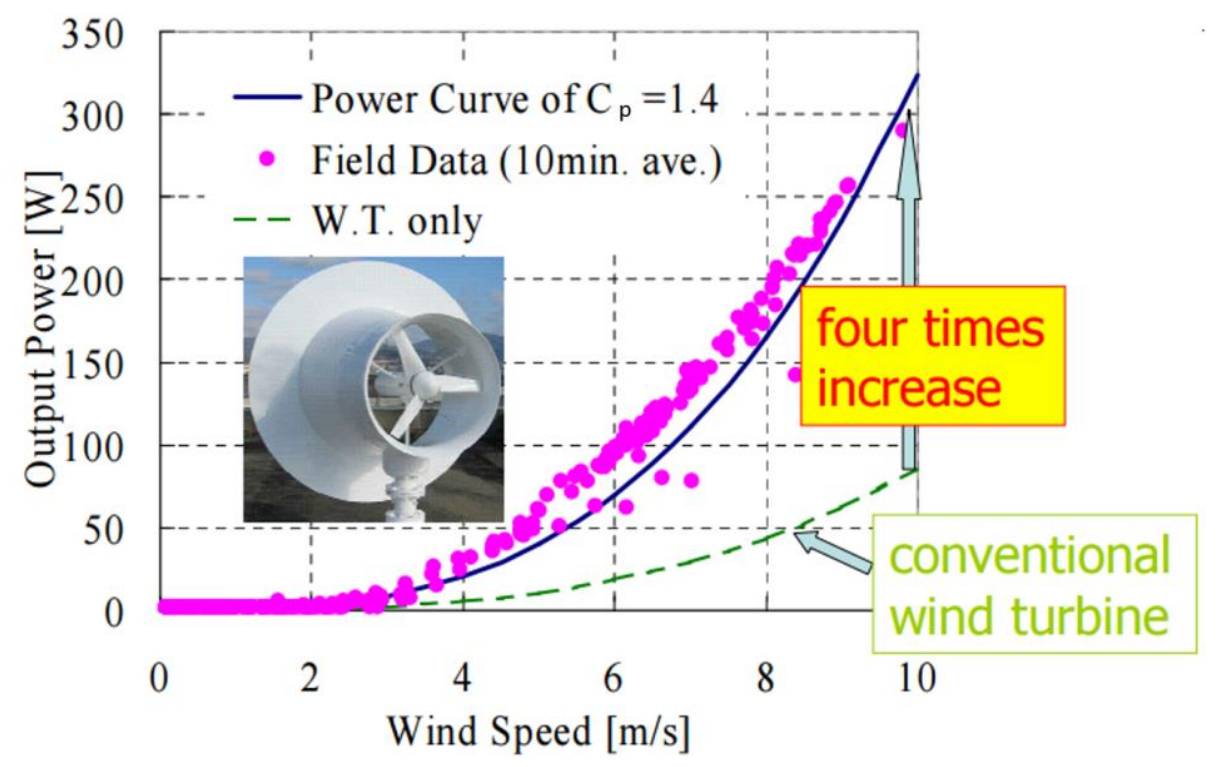

Figure 6 Field experiment of 500W wind turbine with wind-lens (Ohya and Karasudani, 2010) 


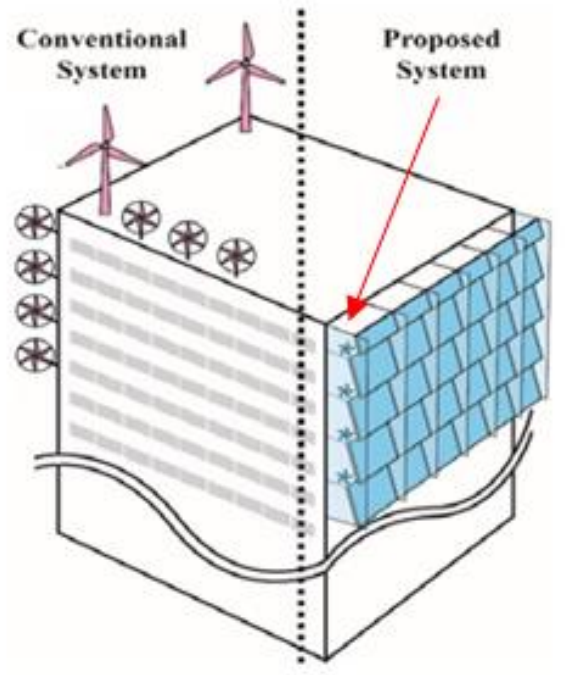

a)

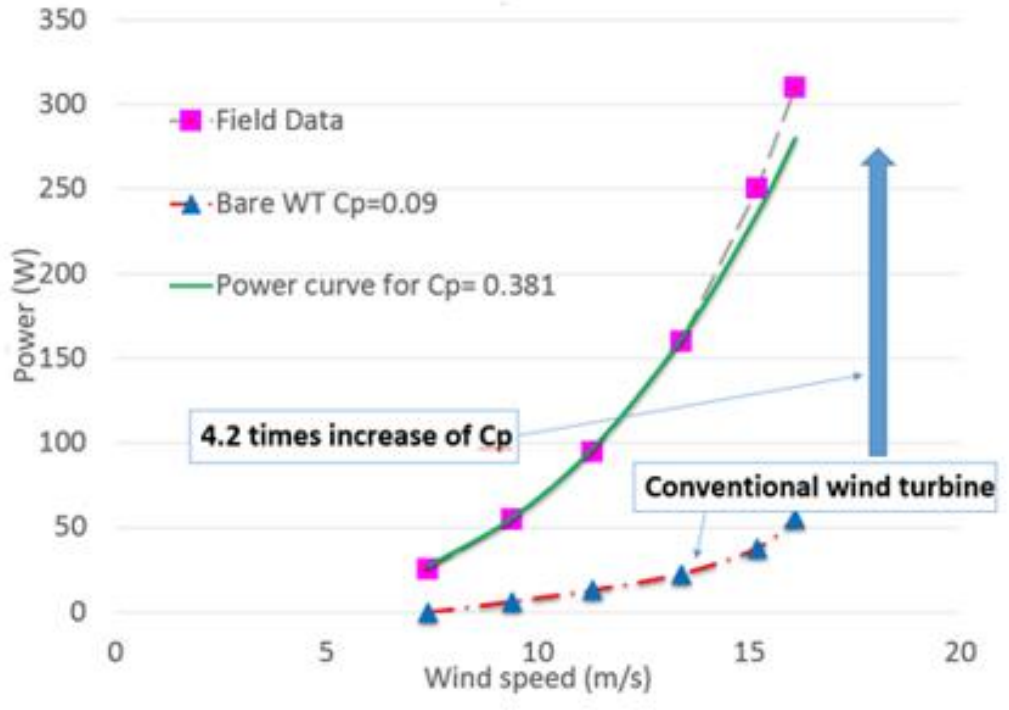

b)

Figure 7 a) Building-Integrated Wind Turbine (Park et al., 2015), b) Performance comparison of BIWT based on data from Saha et al. (2008) and Park et al. (2015)

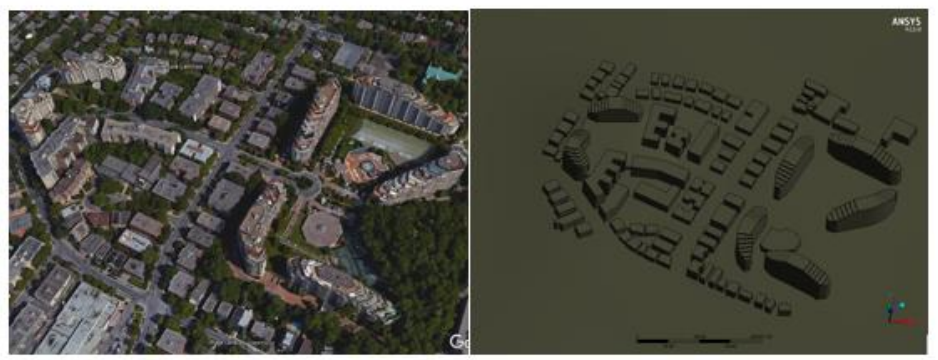

a)

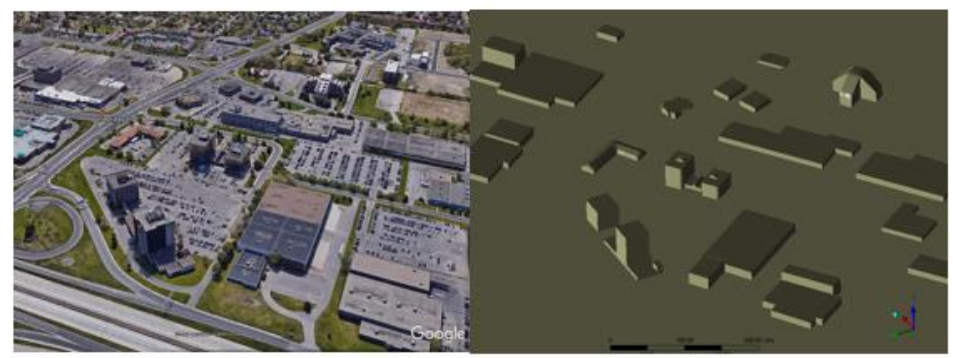

b)

Figure 8 a) Test site in the Cote-des-Neiges borough of Montreal

Google Earth view (left), model geometry (right)

b) Test site in a commercial area in Pointe-Claire, Quebec

Google Earth view (left), model geometry (right) 


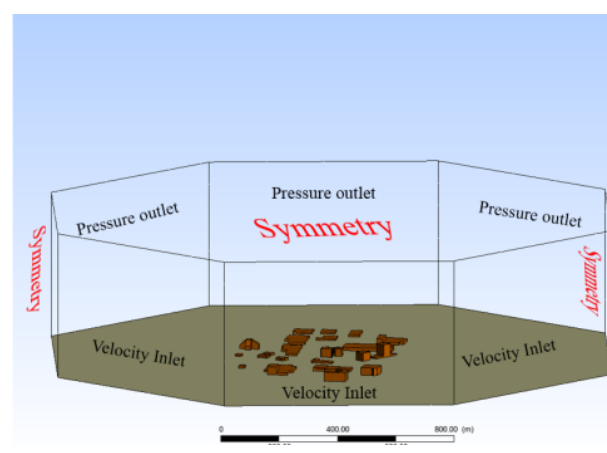

a)

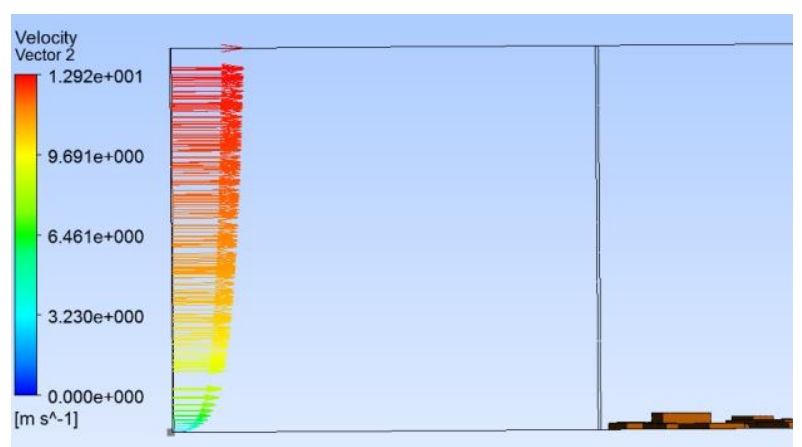

b)

Figure 9 Test site (1) Pointe-Claire, Quebec a) Domain and boundary conditions b) Velocity profile at the inlet of the domain 


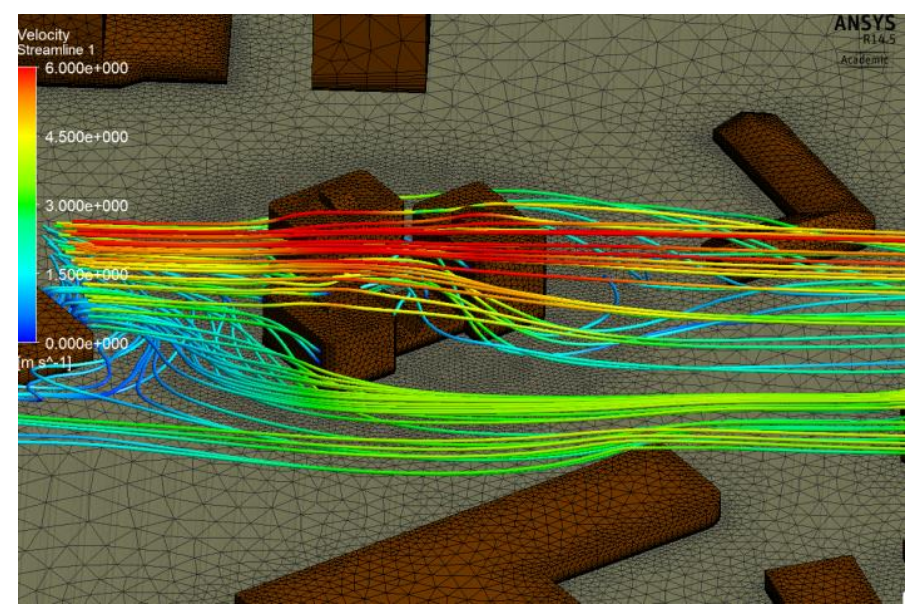

a)

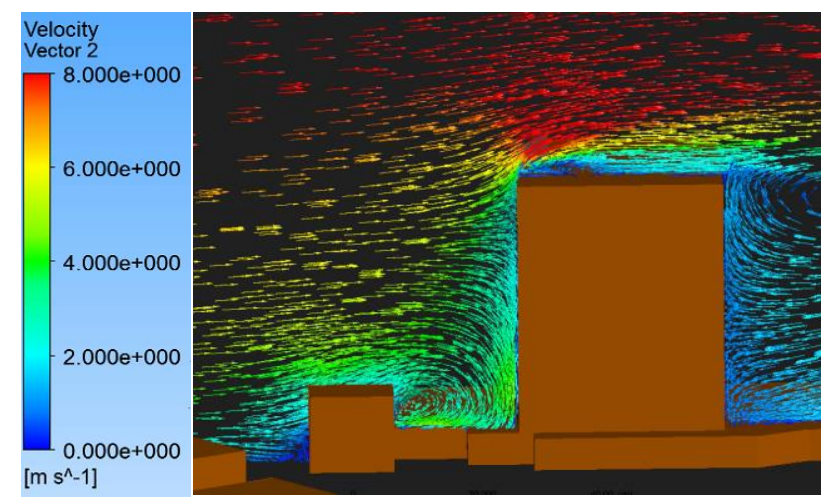

b)

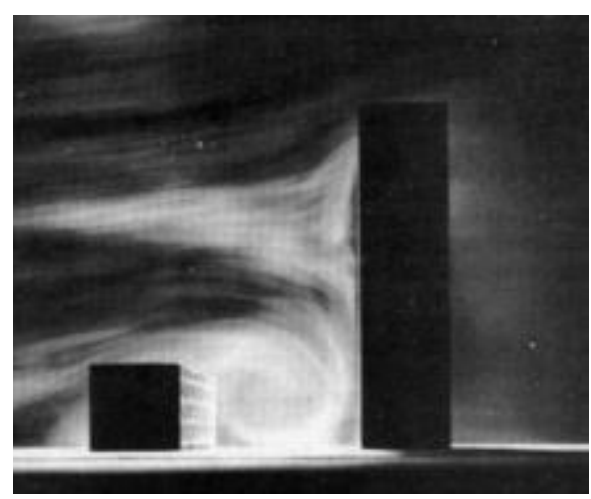

c)

Figure 10 a) CFD velocity streamlines of flow in test site (1) (b) Velocity vector of flow over a building in test site (2) c) smoke visualization of flow in wind tunnel (Blocken and Carmeliet, 2004) 


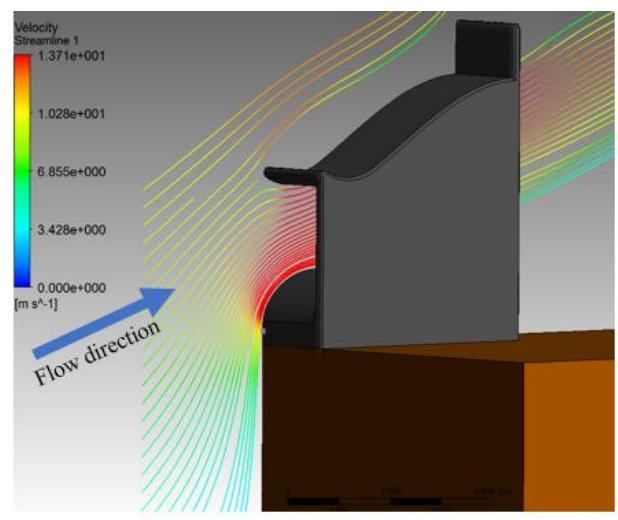

a)

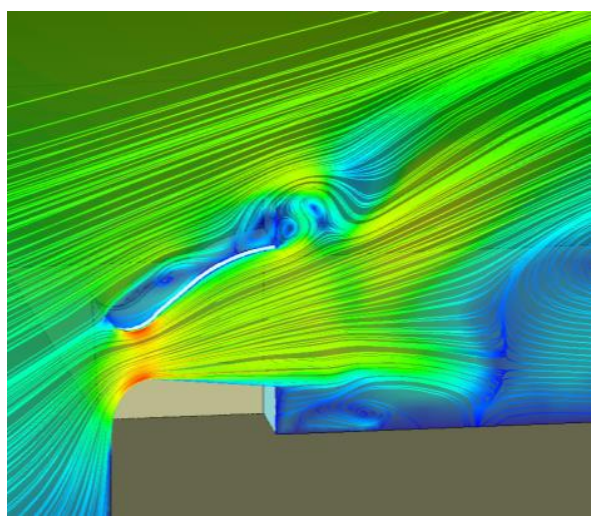

b)

Figure 11 a) Rooftop diffuser shroud mechanism with velocity streamlines b) symmetric cut view of velocity streamlines 


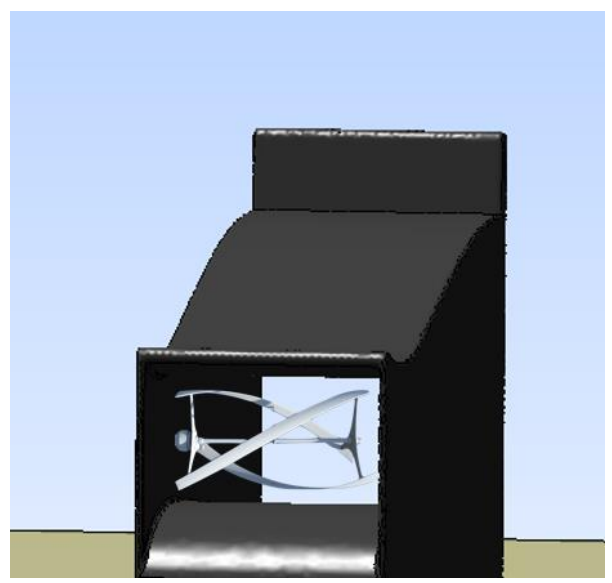

a)

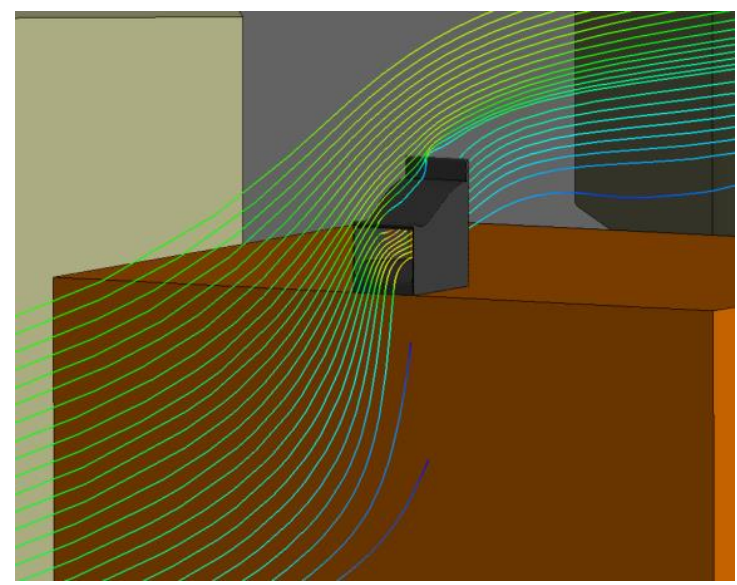

b)

Figure 12 a) Diffuser concept with turbine inside b) diffuser on top of building with velocity streamlines 


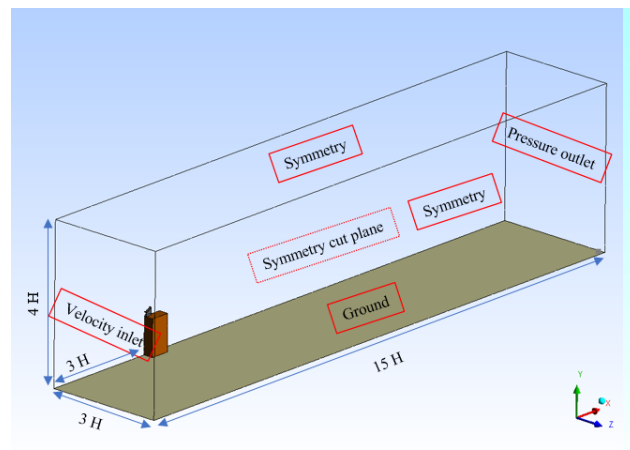

a)

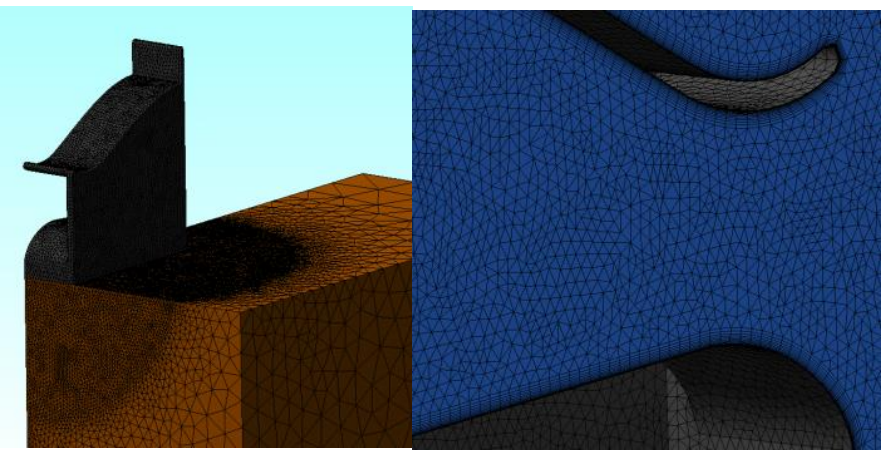

b) c)

Figure 13 a) domain and boundary conditions setup, b) mesh for diffuser on a building c) fine inflation layers on diffuser surfaces 


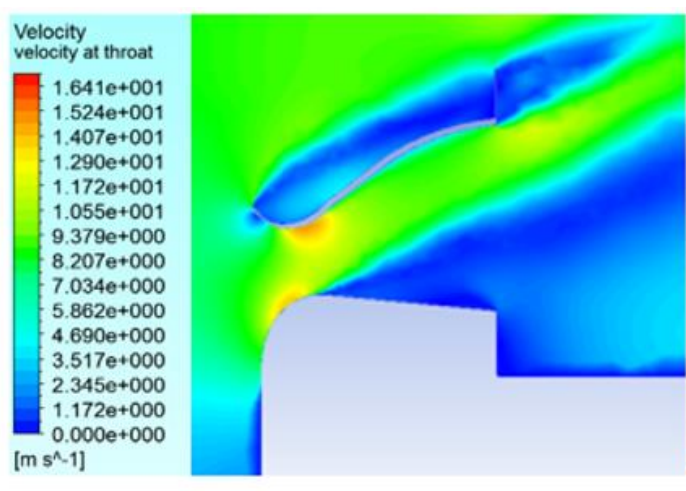

a)

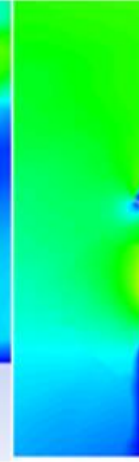

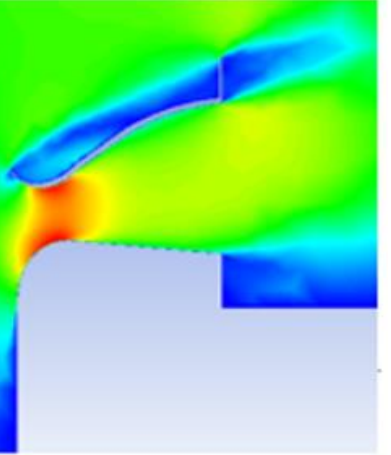

c)
a) at Rey $=170 \mathrm{k}$
b) Rey $=3.4$ million
c) Rey $=17$ million

Figure 14 Flow separation with decrease of Reynolds number

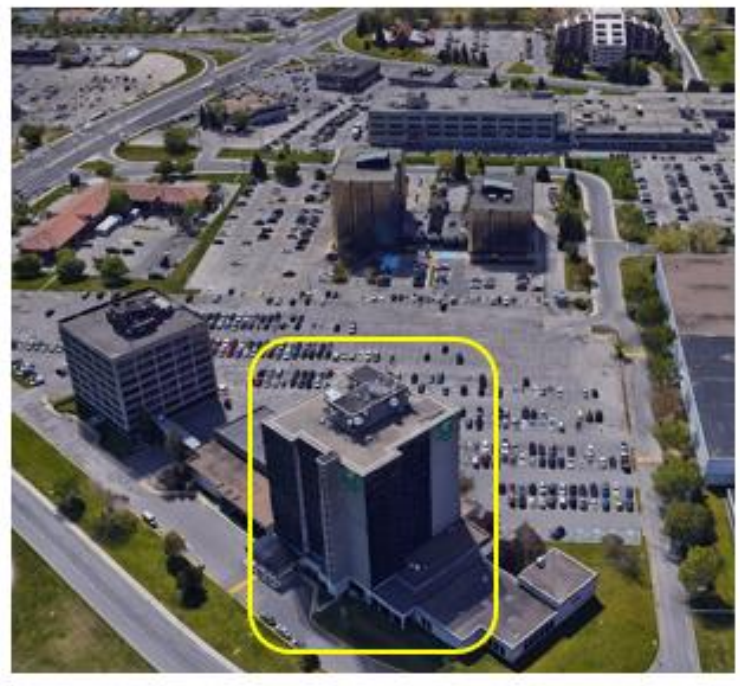

a)

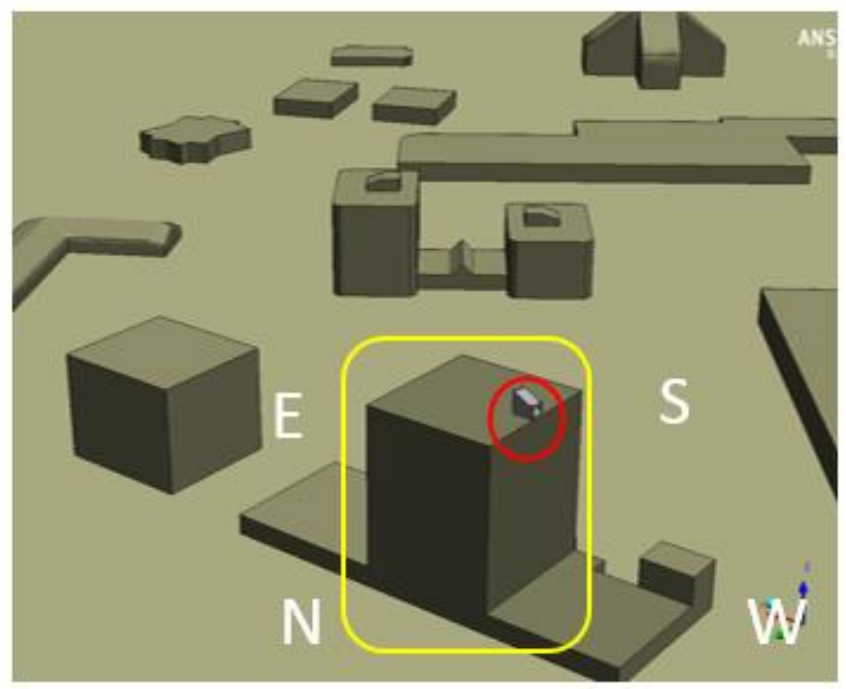

b)

Figure 15 Selected building in the test site in Point-Claire, Quebec

a) Google Earth view b) CFD model 


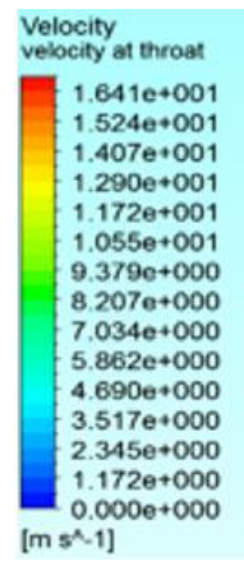
$\left[\mathrm{m} \mathrm{s}^{\wedge}-1\right]$

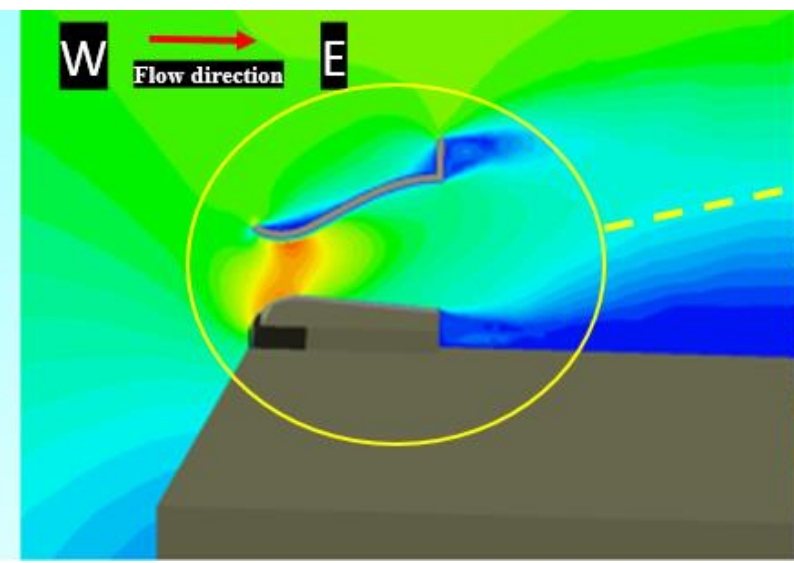

a)

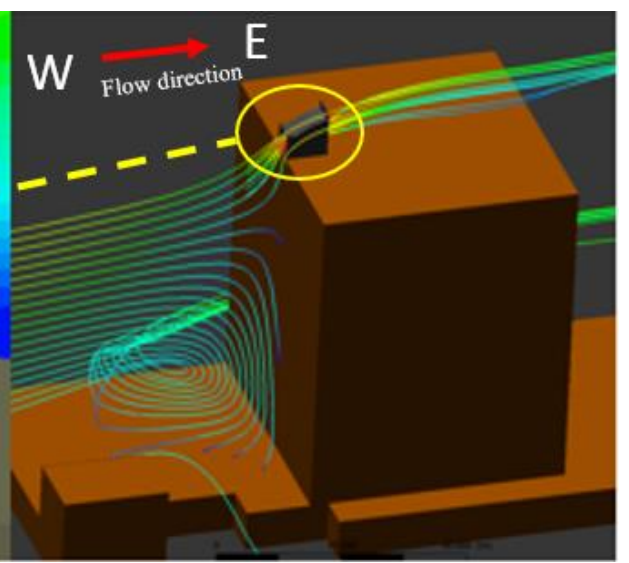

b)

Figure 16 a) velocity contour at the diffuser cut plane b) velocity streamlines in perspective view of selected building 

















\begin{tabular}{llll}
\hline \hline & Urban HAWTs & $\begin{array}{l}\text { Lift VAWTs } \\
\text { (Darrieus) }\end{array}$ & $\begin{array}{l}\text { Drag VAWTs } \\
\text { (Savonius) }\end{array}$ \\
\hline Advantages & Efficient, & Almost as efficient as & Proven products \\
& $\begin{array}{l}\text { Proven technology } \\
\text { widely used in wind } \\
\text { farms }\end{array}$ & $\begin{array}{l}\text { Perform well in different } \\
\text { wind directions and } \\
\text { turbulence }\end{array}$ & $\begin{array}{l}\text { Less acoustic emission } \\
\text { Reliable \& robust }\end{array}$ \\
& $\begin{array}{l}\text { Economical } \\
\text { Wide range of } \\
\text { commercial product } \\
\text { options }\end{array}$ & $\begin{array}{l}\text { Less vibration \& buffeting } \\
\text { and low noise }\end{array}$ & $\begin{array}{l}\text { Perform well in different wind } \\
\text { directions and turbulence }\end{array}$ \\
& $\begin{array}{l}\text { Do not cope well with } \\
\text { buffeting }\end{array}$ & Not yet proven & $\begin{array}{l}\text { Less vibration } \\
\text { Can benefit from turbulence }\end{array}$ \\
\hline $\begin{array}{l}\text { Perform poorly in } \\
\text { changing wind direction }\end{array}$ & $\begin{array}{l}\text { More sensitive to } \\
\text { turbulence than drag based } \\
\text { VAWTS }\end{array}$ & $\begin{array}{l}\text { Not efficient } \\
\text { Comparatively uneconomic }\end{array}$ \\
\hline \hline
\end{tabular}

Table 1. Summary of advantages and disadvantages of urban wind turbines based on Wineur project report (cace et al., 2007) 



\begin{tabular}{|c|c|c|c|c|c|c|}
\hline Turbine name & $\begin{array}{c}\text { Fortis } \\
\text { Montana }\end{array}$ & $\begin{array}{c}\text { Fortis } \\
\text { Passaat }\end{array}$ & $\begin{array}{l}\text { Zephyr Air } \\
\text { Dolphin }\end{array}$ & Ampair & Swift & Turby \\
\hline Turbine type & HAWT & HAWT & HAWT & HAWT & HAWT & VAWT \\
\hline Number of Blades & 3 & 3 & 3 & 3 & 5 & 3 \\
\hline Rotor diameter [m] & 5 & 3.12 & 1.8 & 1.7 & 2.08 & 2 \\
\hline Swept AREA $\left[\mathrm{m}^{2}\right]$ & 19.64 & 7.65 & 2.54 & 2.27 & 3.4 & 5.3 \\
\hline $\begin{array}{l}\text { Coefficient of performance }(\%) \\
\text { from Manufacturer's data }\end{array}$ & 27.56 & 17.20 & 39.57 & 46.93 & 24.05 & 29.08 \\
\hline $\begin{array}{l}\text { Coefficient of performance from } \\
\text { measured annual energy yields } \\
(\%)\end{array}$ & 26.74 & 14.75 & 30.14 & 21.06 & 13.95 & 9.79 \\
\hline Difference (\%) & 4.2 & 16.6 & 31.3 & 122.2 & 72.4 & 197.0 \\
\hline
\end{tabular}

Table 2. Commercial urban wind turbines with their coefficient of performance calculated from both the manufacturer's data and the measured annual energy output(Ani et al., 2013) 
